\title{
Consent, Choice and Stage: the Ambiguous Presence of Women in the KPAC
}

\author{
Ashwathi \\ PhD Scholar, CWS, JNU, New Delhi- 110067. ORCID: oooo-0oo1-6048-7859. \\ Email: ashwathipoz@gmail.com
}

\begin{abstract}
Women had already started marking artistic endeavors and hence situating their identity in their respective fields by the early twentieth century. The left political movements and the socio-cultural movements, which were the by-product of and the supporting source for the political movements, also 'included' women as their members. Plays and theatre were one of the important fields in this respect in Kerala. Women were given 'consent' to make their 'choices' to make public appearances and be associated with these movements. But who were the consent givers to these women? This paper would look at the concept of men's consent and women's choices through the KPAC theatre and the plays. This paper would problematize the question of the importance of men's consent in women's decision making and the choices that they make for themselves. This paper would try to see what role and how this act of men's consenting has influenced the female members of the KPAC as well as in the shaping of the characters in the plays produced by them.
\end{abstract}

Keywords: Women, Consent, Men's Consent, Choice

\section{Introduction}

"It was only after my father, who was in police back then, who was convinced after talking to the members of the KPAC that I was allowed to be part of the play produced by the KPAC".

KPAC Sulochana (Sulochana, 2007)

"My mother never allowed me to dance and sing. Though I was very much interested in those. It was only due to my father's determination that I could continue doing the same and join the KPAC later."

KPAC Lalitha (Lalitha, 2010)

The contributions of women in the social, political, cultural, scientific sphere have been celebrated much ever since it began in the respective fields and the eras. Women working in the theatres were making no fewer achievements. Many women have established themselves very well as actors and singers in their respective language and regions, and some even have received national recognition through their artistic proficiencies. Gender

(c) AesthetixMS 2019. This Open Access article is published under a Creative Commons Attribution Non-Commercial 4.0 International License (http://creativecommons.org/licenses/by-nc/4.o/), which permits non-commercial re-use, distribution, and reproduction in any medium, provided the original work is properly cited. For citation use the DOI. For commercial re-use, please contact editor@rupkatha.com. 
relations constitute a deeply rooted and pervasive system of oppression - patriarchy. This form of oppression remains intact, despite changes over time and differences that are, for example, related to race, class, culture, or sexual preferences (McGuinness, 1993). Women were not allowed to sing or act in public and women entering the stage was a daring step. Sajitha Madathil, in her work on the history of women theatre artists, discusses the shift and the life of many artists and about the "daring steps" that women took by entering the theatre. Kerala People's Arts Club formed in the year 1950, as a parallel organ to the IPTA, becomes one of the important areas to be looked. Some of the women left, some have stayed for a while, and some have become famous by dedicating themselves to the faculties they were gifted with or that they had learnt eventually. Artists like Paambakuda Leela, Rajamma, Prasanna, and others like them (all these women worked with the KPAC and in a few films too) probably left after a while, and any documents about them are rarely found. Vijayakumari started her theatre group Kalidasa Kalakendra with her husband O. Madhavan, and artists like KPAC Lalitha and Kaviyoor Ponnamma left to make their future in the films. But how did they reach here? What if they were not allowed to pursue what they wanted to do? What if consent was 'not given' to make their choices in a period when it was a taboo for women to perform in public? And how did they stay? It is in this context that the factors contributing to women making their choices and the difficulties they face to sustain it become important. Precisely, there is a need to look at the women who have worked with the Kerala People's Arts Club (KPAC), like KPAC Sulochana, KPAC Lalitha, Vijayakumari, Sudharama/ Gomathi as well as the kind of the female characters in the plays produced by them.

\section{Consent and Choice}

Consent had become a much- debated term starting from the seventeenth century when John Locke had defended the claims of freedom of the people from their birth against the claim of subjugation to the monarch in his Two Treatises of Government (Nyland, 1990). He had first come up with the idea of consent in the social contract that exists between the government and then people, where the government exist due to the consent given by the people to protect their rights and hence the people also had the right to overthrow that power if the governing body fails to do so. In his Two Treatises of Government, he says that "men are by nature free and equal against claims that God had made all people naturally subject to a monarch". And when he said "men" he meant men as the generic category that excluded the women, which could be found in the further claims that he makes in his work. "This idea that government is legitimated by consent of the governedor at least by those among them who were considered capable of giving consent, a group that often excluded women ..." (Johnston, 2010). "The modern liberal democratic societies have been characterized by an ever-growing domain of personal sovereignty, making consent salient across a wide swathe of human activities including sexual relations, employment, medical care, buying and selling, medical research, professional relationships and so forth" (Wertheimer, 2010). The choices that confront individuals ultimately rest on abstract concepts - consent and power - which are removed from the 
circumstances, relationships, and lives involved (McGuinness, 1993). It would not be wrong to claim the act of consenting as the potential by-product of choice making. The choice theory is based on the premise that every individual only has the power to control themselves and has limited power to control others. It allows one to take responsibility for one's own life and at the same time, withdraw from attempting to direct other people's decisions and lives, which in social science is termed agency. It is this tension between agency and consent that would be considered further.

It could be suggested that the term consent has been often interchanged with or used to imply sexual consent. Most of the recent discussions around the concept of consent has been approached from the perspective of women, as women's right, in terms of their body and their sexuality (Pateman, 1980), and apart from that in relation to law, where electing a government was also apparently consenting to the rules and the decisions that the governing body would take (Beran, 1977), regulations they make and the debates around the idea of obeying rules (Raz, 2014) and also the regulations concerning the age of consent (Fischel, 2010). This paper looks into the idea of men's consent that they 'give' to women, in the form of authorization, orders, permission, approval, and acceptance manifested through various forms of the patriarchal system. Although it is difficult to separate these terms, they imply specific meanings and functions. For it could be understood that between the act of making a choice and fulfilling them those aspirations through actions, there lies this blurred yet the significant line of the consent of the male member of the family that it goes unnoticed.

The Kerala People's Arts Club, popularly known as the KPAC, from its formation in the 1950 os had creatively indulged in addressing and demonstrating to the people the socio-political issues around them and bolstering the strength of the people through the plays and the songs produced by them. The corpus of literature that they have created, as part of the need for the cultural wing of the communist movements, was always in dialogue with the period of their production. It dealt with the primary concerns each period has faced- caste and class oppression, gender inequality, feudalism, disease-related laws, the wage of the factory workers, and so on. The prominent plays were also produced in a period when the socialist ideology had its complete influence on the people as well as on the literature produced. But neither the plays nor the movements itself questioned the way power relations that worked between people of a different gender. I would argue that the KPAC and the left political movements have failed to question, understand and interpret the idea of strong liberated women and have instead deterred women's identity by entrapping the idea of their choice in the web of men's consent to establish the self.

Karl Marx and Friedrich Engels had proclaimed in the Manifesto of the Communist Party (1848) that in a socialist society "the condition for the free development of each is the free development of all." But in a state, the individuals are bound by the moral requirement to obey the law of one's country, for they are bound by the political obligation (Beran, 1977) and the state takes the image of a "duty imposer", as argued by Leslie Green (Klosko, 2018), able enough to change people's normative status, by imposing duties and other requirements on them. And the state being historically 
masculine, it is the men who are in power, the ruling class. Women were deprived of decision- making powers or hierarchical dominance as in the $19^{\text {th }}$ century, says Judith Brown. Both within the family and other institutions women were supposed to listen to whatever was instructed to them and take decisions only when backed by a male member of the family, without even considering the opinions of the female members of the family. Carole Pateman's argument is that women are not fully constituted individuals in civil society. Hence, consent is not their privilege (McGuinness, 1993). It could be argued that unlike the hierarchies that existed between man and women, men shared an equal power position at least even within the family, while consent from the male member of the family was always important for women to move forward most of the times. Chris Nyland in his criticism of "John Locke and the Social Position of Women" argues,

As the Royalists' reading of the relationship between Adam and Eve, as revealed in the book of Genesis, convinced them that God had decreed that husbands had the right to expect unquestioning obedience from their wives it followed that the father was the senior parent within the family. This meant that children, while bound to honor both their parents, owed their primary allegiance to the will of their fathers. Paternal authority was therefore natural and divine in origin in that subordination of wife to the husband was decreed by God and subordination of child to father was grounded in nature which God had created. (Nyland, 1990).

Based on the study that I had conducted for my MPhil on regional autobiographies and memoirs by women of the communist activists (Ashwathi, 2016), it was understood that the idea of family was private space where the reformer man would ultimately 'return' after they had made all the 'sacrifices' for the people. And despite having proclaimed about the ideas like equality of all classes and caste, education, and distribution of land rights, many of them did not allow these progressive thoughts to cross the threshold of their ideal homes where woman performed strict gender roles.

The organizing of the socio-cultural movements led by progressive thinkers is also interesting parts to be studied. The aim of progressive changes never reached the point where women would also be making opinions and be an active member of the organizations at the structural level. The organizing of the KPAC itself is an interesting category to look at for that matter and the stagnancy at that level with the absence of a single woman in the committee evident even now. Neither have women come to the forefront nor they have taken any women assigning important parts in relation to the play such as playwrights, directors, lyricists and composers which was a task that included the use of their "brain" (Anantharaman, 2008), other than singers and actors, which has the same dignity as other artistic ability. The Kerala People's Arts Club, popularly known as the KPAC, was founded in the 1950 s with a similar agenda by the then law college students G. Janardhana Kurup. KKK Kurup, Sukumaran and P. Narayanan, envisaging a theatre group that could represent through the medium of play the experiences of the ordinary people. It transformed itself into a proper organization only in the year 1953 with Adv. Janardhanakurup as the president, Rajagopalan Nair as the secretary and Kambiserry Karunakaran, Thoppil Krishnapillai and O. Madhavan as the members, KPAC later 
became the state level part of the communist party after this only. And where they successfully portray the real life characters through their plays, they also express the power of male members in the institutions like family and in theatre groups through their authority to give consent which in turn had the ability to control the female body and their sexuality by making them internalize the 'fact' that how significant is that consent to them. KPAC Sulochana narrates an incident where she was asked to change to a simple saree when she dressed for a music concert by one of the male members of the theatre group (Sulochana, 2007). She was asked to do so in the pretext of being a role model to the people so that they also follow the same simplicity in their lives. It could be argued that, even the older women like mothers, aunts or grandmothers of the family could not give any opinion and it was also difficult to make them understand that it was not that they cannot give any opinion, but they did not have the authority to do so. And historically, women eventually ended up believing that they did not have any say in any of the matters in the family or when men have any serious discussion.

While the IPTA, which also served as one of the motivations to the KPAC, was not ideologically sectarian and provided space to those holding milder political views, though its founding members and the stalwarts associated with it had Marxist leanings, the KPAC was formed as part of the need of a cultural wing to the communist party to reach out to the common people addressing the socio-political issues of the period (Menon, 2001). The absence of women in the decision making bodies and in the production work like scriptwriting, direction, songwriting, and music composition, actually shows the least importance given to women and their opinion. That is crossing the societal taboos, which itself was controlled by the men and other patriarchal rules of caste and gender, did not gain them space which required a certain amount of 'brainstorming'.

It could also be suggested that apart from the privilege of being educated it was also the financial independence of men that helped them to be part of the movement, as they were the ones who were the earning members and also the independent ones unlike most of the women. The KPAC was a group of "bright" students of the law college and the university, who were later joined by various people of the Communist Party, activists like Thoppil Bhasi, and formally trained artists like Sambasivan, G. Devarajan etc. On the one side where O. Madhavan, one of the prominent actors of the KPAC and who was with the KPAC almost since its formation, states that KPAC was the result of the direct involvement of the communist party, while the History by Mohandas claims that the decision to form an arts club came from N. Rajagopalan Nair, who was a law student as well as the elected member at Travancore, because they were sure that it was difficult to continue practicing law as a profession. Yet, it was not formed with a pre- permission from the party hence they could not get any monetary help from them for that matter, which was further resolved by the help from Advocate Rajamani, who belonged to a well to do family. Prof. MP Paul, who supported the founders with valuable suggestions, alter joined them after leaving his job at St. Thomas College, Thrissur with the assurance that he had a private tutorial college that could sustain him and his house nearby was the hub of literary discussions. 
This concept of consent, it could be suggested that also created a certain kind of masculinity that was based on class, caste and the status in the society, which apparently had the potential to influence this consent. The advantage of having these privileged members in the KPAC could be further validated through the consent given by the guardians of the female artists like P. Sulochana, Vijayakumari, KPAC Lalitha, Kaviyoor Ponnamma and Gomathi/ Sudharma. Sulochana's father had allowed her to sing and act for the plays despite him being a policeman, was that the Rajagopalan Nair was an MLA and Rajamani was an advocate. Her father was happy to see that the organizers were "gentlemen and held a prestigious position in the society", as recorded in the History (Mohandas, 2002). So was the case with the actress Vijayakumari. She was allowed to act in the play on the request of her relative Gomathi/ Sudharma only when she conveyed that to her father that those in the KPAC were "naadakkaaralla", not theatre people, instead they were the communist party activists and their plays were written by Thoppil Bhasi who was in jail (Mohandas, 2002). Lalitha, an actress in the Malayalam film industry now, entered KPAC only after it had earned a title of its own (Lalitha, Interview, 2019), while Kaviyoor Ponnamma was introduced on the request of LPR Verma as she had learned classical music and her efficiency drew them to her. Going back to the opening lines of this paper, which were taken from their respective biographies, KPAC Lalitha, who had acted in many plays of KPAC but is now a prominent actress in Malayalam, and KPAC Sulochana, one of the prominent singers of the KPAC and also acted in few of them, specify that it was not possible for them to take any decision independently and in Lalitha's case her mother's consent was not at all taken, though it helped her to get into the KPAC theatre group, which for her was like her dream come true (Lalitha, 2010). While on the other side, Thoppil Bhasi, who had written most of the plays for the KPAC during its early years and also directed plays of even other playwrights, was formally trained to be an Ayurveda physicist. But he chose political activism despite the differences from his father, who after a certain point even stopped saying anything to him, despite after having experienced tortures in the hands of the police on days when Bhasi would be underground (Bhasi, 2017). He never had to take any consent to follow what he wanted to do. The juxtaposition of these incidents forces us to think of how consent works, especially situations when one talks about women and their achievements. It could be possibly argued that none of these actresses would have been granted to act if they were called by any other theatre groups specifically, formed by the working class people and also as mentioned before the cultural centers formed by the factory workers and the peasants, aimed at training the children of the poor families, so that those children could further help them to take forward the experiences of their class to the people. KPAC, on the other hand, wanted and mostly selected either trained people or those any prior experience, unless in dire situations when the actors could not be there for the scheduled programme or they left the group after the shows were booked.

The demarcation between the productive and the reproductive sphere that serves as the basis for women's oppression was seen in the kind of work women did in the KPAC group. KPAC Lalitha had said in the interview that it was women who cooked and served the food for the entire group (Lalitha, Interview, 2019) and this gave them the feeling of a 
family. This suggested that even if women came out of their homes to work or to be an artist, earning for themselves, there was a constant reminder of what the men understood as the capabilities of women were despite them having achieved certain success with their talents and hard work and also financially independent, and a woman was naturally supposed to do while recreating the idea of family even within these 'progressive' theatre clubs. The songs in a similar fashion demonstrate men's increasing exclusive role in production and women's central role in reproduction, could be seen addressed in the form of desire for love and to "form a nest together" (Kurup, 2000), which might indicate family or home and in turn holding the romantic vision of the proletarian household. It could be argued that just like the socialist movements despite talking of the economic equality of women, talking of their rights and oppression, the KPAC like other movements only pushed back women to the institution of family where there was a clear divide between production and reproduction, in turn 'emotionally and mentally' blocking women from moving out of the institution of marriage and family. Even when the communists aimed to do away with the status of women as mere instruments of production, they were not ready to give away with the idea of women's body as the means of reproduction contributing to the idea of family, which is one of the important roles that accomplishes a woman despite all the achievements that a woman would make.

\section{Consent and the Writer}

Consent was also clearly marked by caste. It could be argued that in the literary representation it was the consent of the writer and the lyricist, who holds the power position as men and as the person who had done the task with the 'brain', to decide upon characters in the play and the representations in the songs. It was a the upper caste men who decided whom a lower class women should fall in love with, and it was a strict no to a Dalit woman falling in love with an upper-caste women. In the play Ningalenne Communistaakki, the second play presented by the KPAC and which established the name of the KPAC and helped achieve its success. As part of the progressive ideology, there was the introduction of a Dalit pulaya woman Maala as the female protagonist and bringing her to the forefront of the stage. Alongside there was also the bringing the character of the upper caste Nair woman Sumam onto the stage and providing her with progressive thoughts, making an older man Paramu Pillai as the male protagonist of the play and the set of songs being introduced into it adding more emotions to the scenes. Though the introduction of a Pulaya girl was hailed as revolutionary and progressive, what goes unnoticed in the plays by the KPAC starting from Communistaakki is that caste and gender oppression is intertwined with the plot in such a way that it becomes difficult to read it in that way despite talking about the abolition of the caste oppression and the denial of rights based on their caste. The non-acceptance of Mala's love for Gopalan was checked by the character Mathew reminding her about the duties and responsibilities of Gopalan hence arousing in her the revolutionary thoughts. She was also reminded to empower herself to fight against the caste oppression and the denial of rights pushed on the people of her community. Gopalan also when later comes to know about this makes a 
statement that he loves Mala as a sister. While on the other side the dedicated Gopalan fantasizes Sumam and they fall in love for each other, and this love as a medium converting Sumam into a progressive woman to make her a better match for the communist Gopalan. The play Thulaabhaaram also conveys a slightly different but similar idea. The upper class-caste Vijaya after the death of her father, abandoned by her friend Vatsala and her lover, goes to her old factory worker Ramu and instead of getting married, as the text says, she "lays the bed for her husband" (Bhasi, Thulabhaaram, 1968). Ramu after a few years dies in a fight with the management of the factory, where they had been fighting to raise their wages and Vijaya kills her children by poisoning them with no other option left with her to sustain them. Two things are emphasized here-firstly, a woman always needs a man to protect her piety and second is that the union of people belonging to two different castes and classes cannot be agreed upon by the society. The play Mudiyanaaya Puthran where the character of Rajan, the younger son in an upper caste family, denied of property and other rights by his brother, becomes a rebel and ends up in a romantic relationship with Chellamma, who belongs to the pulaya community. There also this union is not allowed by throwing Rajan into the jail for the murder that has happened and the story ending like that.

It would not be wrong also to argue that women were considered less intelligent and knowledgeable when compared to their male counterparts both in the KPAC and in the play. There is an episode when a counter play was written by Janardhanakurup and Rajagopalan Nair when the order for the prevention of staging Ningalenne Communistaakki had come out. The play has a scene where it goes to be censored was given to the women in the house who do not have any artistic sensibility to decide upon how a good work of art looks like. Those who came up with the prevention act are compared to that of these women, holding how lowly they think of women (Mohandas, 2002).

The family also came under the aegis of morality and was given high consideration in almost all the plays. All the female characters appear family bound, performing the stereotype roles of daughter, wife, sister, mother and grandmother. Not only did the parameters of the party was followed in the KPAC, but high moral standards were also strictly followed, upholding the idea of the collective alongside with the strong support from the party. And the advocates of this being the male members of the committee. There are songs written on the fishermen community where their act of fishing, going to the deep sea fighting the waves, staying away from their beloved for a long time and comparing this vigour and sacrifices to that of the peasant revolts and the workers movements.

But along with this comes the sorrow of the women at home and them awaiting their husbands which indirectly refers to the belief among their community people that if the women do not stay loyal or preserve their chastity will lose their husbands to the sea. This could be considered as one of the ways where female bodies are controlled in the name of belief by inflicting fear. And the lyricist reproducing the myths to reaffirm the 
notion of morality as they are the ones 'burdened with the task of ascribing and holding up their respective roles to men and women'.

\section{Consent, Education and Work}

The lack or complete absence of any right of women on their bodies was also reiterated while projecting them as strong and as able decision-makers. In India, abortion was legalized only after 1971. Before that it was considered illegal even if it was a rape unless it was a mentally affected woman who was raped, eroding the rights that women have their bodies. Sharada of Mooladhanam conceives the child of her husband's friend Madhu, who cheats her under the pretext of bringing out her husband Ravi from jail. In the end, Sharada is shown to be "polluted" but her husband, standing mum but accepting her for "he has a big heart" that could hold her hands again. Interestingly there is no reference to the word or the act, unless Sharada says that "I have given you everything I had and why are you here again" (Bhasi, Mooladhanam, 1958) or that "I am polluted" (Bhasi, Mooladhanam, 1958) and also Madhu going unpunished by any means, and a woman punishing herself for the act that she had chosen to do for the sake of the family. The playwright has not given women the right to use the taboo words like rape directly, which could probably mean that the language already being masculine, women need permission from men to use them or that the men could control even the usage of certain words. It could be argued that achieving the aim and fulfilling the desire of success has also been kept below the sexual desires and the idea of "accomplishment with motherhood only". Sharon Smith says, "Women professional who postponed marriage or children until they reached their thirties or beyond looked back and realized they had made a terrible mistake" (Smith, 2005). Where the women's movements had been asking for equal wages and maternity leaves, the KPAC plays were on the other side promoting the importance of family at the cost of education and a secure job for women. Here the play Kanyaka, another play by the KPAC, serves as the mouthpiece of the society which is adamant about making women fulfil their stereotype roles is about Devakikutty who is a wellknown lawyer but develops a strained relation with her sister Bhaarati, who is married and also has a child. It could be understood that there were moments where she could be seen blamed for not being a mother or not knowing the emotions of a mother, getting "jealous" of her sister while she spends time with her husband, etc. It is also implied in the play that it difficult to find a husband for an educated woman. As a solution to all this and to "complete herself" she resigns from her job and "leaves to live a happy family life with her clerk, Velupillai". Till then Velupillai is silent and does not utter anything other than clerical matters to Devakikutty and neither does he say anything when she gives up her hard-earned job, and they leave the place together for better.

Within the family, the economic factors, have also played a role in shaping the personal aspects of the unequal relationships between men and women along with the erosion of the right to choose. But the relationship with the moral aspects, the concept of the ideal family, duties and responsibilities, etc. mask the economic difference as the reason for the oppression and in sustaining the hierarchy. Koottukudumbam is another 
similar play. But it does not make the female protagonist working as a theatre actress to leave her work; instead it portrays the 'loss' she had to face when she chose her profession above marriage. The female protagonist Shyamala, to sustain her devastated Nair tharavadu, takes up then offer as an actress to and also to make money to help her fiancé Ramakrishnakurup to complete his studies, was as asked to stop from further acting in the plays. Though it in a way reflects the moral constraints and the thoughts of the society then, but it was also simultaneously the masculine consciousness that could not think of a woman earning for the family, who in turn punishes her by marrying her friend, for making her choice of not giving away the "work" that has supported them during their difficult times, establishing that it was not just the financial independence that is sufficient for a woman unlike Ramakrishnakurup. Even though women are shown to make their 'choice' mostly, it is shown in such a way that these decisions made against the morals of the society ultimately suffer. In Sharashayya, the sequel to Ashwamedham, Sarala leaves her husband Karunan who always ridiculed her and women in general "lack of reading habits" and "idiocy" and she finds "love" in Mohan but when she approaches him for marriage he avoids her by saying that "we can continue like this" (Bhasi, Sharashayya, 1964) questioning her morality, implying that women cannot choose their partners.

\section{Conclusion}

While it is imperative to acknowledge the significance of the KPAC as a movement and a moment in the cultural history of Kerala and the left political movements, it is at the same time to be critical about the drawback of their artistic productions itself that has disguised the upper class male judgments and posed it toward the people. It could be seen that despite being the advocate of progressive ideology, the KPAC as an organization and the artistic representations by its writers have channelized their control on the women and female bodies through the upper caste- class male authority, which like the state, assumes all the power consented to them by the people to govern them and take care of their wellbeing. As Kate McGuinness also quotes that the rulers have power because the ruled gave consent to it (McGuinness, 1993). It could be argued that it is the women consenting to the need authorized consent of the men on their ambitions and desires that promote this kind of hierarchy, potential enough to pull them back from achieving what they want. Looking at these issues, it could be argued that there is much more to be achieved than just fulfilling the aspiration and bringing them into action. There is a much more long history laid behind all these achievements which need to be understood from a feminist perspective. John Locke says, "People are by nature free. They originally exist in a state of nature, which is a situation without government, and so without moral requirements to obey. Because people are naturally free, nothing can remove them from this condition but their own consent (Beran, 1977). 


\section{References}

Anantharaman, G. (2008). Bollywood Melodies: A History of the Hindi Film Song. New Delhi: Penguin Books.

Ashwathi. (2016, July 22). Activism and Narrating the Self: Memory and Experience in Women's Autobiographies from Kerala. New Delhi: Jawaharlal Nehru University.

Beran, H. (1977). In Defense of the Consent Theory of Political Obligation and Authority. Ethics 87.3, 260-271.

Bhasi, T. (1958). Mooladhanam. Quilon: M. S. Book Depot.

Bhasi, T. (1964). Sharashayya.

Bhasi, T. (1968). Thulabhaaram. Kottayam: Sahitya Pravarthaka Co-operative Society.

Bhasi, T. (1976). Ninagelenne Communistakki. Kottayam: Sahitya Pravarthaka Cooperative Society.

Bhasi, T. (1986). Koottukudumbam. Thiruvananthapuram: Prabhath Printing and Publishing.

Bhasi, T. (2010). Ashwamedham. Thiruvananthapuram: D.C. Books.

Bhasi, T. (2016). Mudiyanaaya Puthran. In T. Bhasi, Thoppil Bhasiyude Kritikal. Thiruvananthapuram: Prabhath printing and Publishing.

Bhasi, T. (2017). Olivile Ormakal. Thiruvananthapuram: Prabhath Book House.

Bhasi, T. (n.d.). Ningalenne Communistaakki.

Fischel, J. J. (2010). Per se or Power? Age and Sexual Consent. Yale Journal of Law E Feminism 22.2., 279-341.

Johnston, D. (2010). A History of Consent in Western Thought. In F. M. Wertheimer, The Ethics of Consent: Theory and Practice. Oxford University Press.

Klosko, G. (2018). Consent Theory of Political Obligation. In P. S. Müller, The Routledge Handbook of the Ethics of Consent. New York: Routledge.

Kurup, O. (200o). Poothamarakkombukalu. In KPAC, K.P.A.C. Naatakagaanangal: Collection of Lyrics (p. 27). Thiruvananthapuram: Prabhath Book House.

Lalitha, K. (2010). Katha Thudarum. Kozhikode: Mathrubhumi Books.

Lalitha, K. (2019, January 21). Interview. (Ashwathi, Interviewer)

McGuinness, K. (1993). Gene Sharp's Theory of Power: A Feminist Critique of Consent. Journal of Peace Research 30.1, 101-115.

Menon, N. R. ( 2001, May 12). Path-breaking plays. Frontline 18.10. 
Mohandas, D. V. (2002). K. P. A. C. yude Charitram [History of the KPAC]. Kayamkulam: Kerala People's Arts Club.

Mukhopadhyay, N. (2018, April 03). Past Continuous: Why IPTA Has a Special Place in India's Cultural History. Retrieved from The Wire: https://thewire.in/culture/pastcontinuous-why-ipta-has-a-special-place-in-indias-cultural-history

Nyland, C. (1990). John Locke and the social position of women. Economics Working Papers, 1-32.

Pateman, C. (1980). Women and Consent. Political Theory 8.2, 149-168.

Raz, J. (2014). The Obligation to Obey: Revision and Tradition. Notre Dame Journal of Law, Ethics \& Public Policy, 139-155.

Reich, O. (2017, November 06). \#ToObeyOrNotToObey: Consent Theory. Retrieved July 20, 2019, from Liberties: https://www.liberties.eu/en/news/consent-theorytoobeyornottoobey/13386

Smith, S. (2005). Women and Socialism: Essays on Women's Liberation. Chicago: Haymarket Books.

Sulochana, K. (2007). Arangile Anubhavangal. Thrissur: Current Books.

Wertheimer, F. M. (2010). Preface. In F. M. Wertheimer, The Ethics of Consent: Theory and Practice. New York: Oxford University Press. 